\title{
Educação Ambiental frente à Reforma do Ensino Médio no Brasil
}

\author{
Environmental Education in face of the Reforma do Ensino Médio in Brazil
}

Educación ambiental en la cara de los cambios en la Reforma de la Educación Secundaria en Brasil

Laís Naiara Gonçalves dos Reis Professora Doutora, UEG, Brasil geografalais2013@gmail.com

\author{
Marco Túlio Martins \\ Professor Doutor, UEG, Brasil. \\ marcogeografia2008@yahoo.com.br \\ Daniela Almeida Rosa \\ Professora Especialista, UEG, Brasil \\ danikitte07@gmail.com
}


O conceito de educação ambiental se diferencia pelos vieses do local de aplicação desta. A formação e desenvolvimento do indivíduo também acontecem nas instituições de ensino e, portanto os princípios que compõem a recente alteração da LDB para Base Nacional Comum Curricular (BNCC) precisam ser claros e dotados de pedagogia para que a educação ambiental seja desenvolvida nas grandes áreas propostas, uma vez que os alunos deverão optar por uma área. A preocupação é que não seja possível desenvolver em sua plenitude a educação ambiental por meio da proposta de flexibilização da grade curricular. Este artigo tem como objetivo avaliar o caráter pedagógico da educação ambiental nas alterações da Reforma do Ensino Médio brasileiro e na BNCC, nos conteúdos itinerários das Ciências da natureza e suas tecnologias e Ciências humanas sociais e aplicadas. Para tal, foi realizado o levantamento bibliográfico na literatura científica sobre a educação ambiental: teoria e aplicabilidades para a construção de reflexões sobre a Base Nacional Comum Curricular (BNCC) e a sua abordagem de EA. Após a leitura dos PCN's, ficou-se a impressão de uma escola ideal, muito além daquela contemplada pela infraestrutura das escolas públicas brasileiras, sobretudo, no que tange aos aspectos de laboratório. Por ter característica continuada, a escola deverá adotar uma política e práticas que permitam o desenvolvimento integrado da Educação Ambiental no âmbito escolar. Para tal, alguns temas podem ser desenvolvidos na escola e em sua comunidade. Sugere-se um projeto start a partir da investigação da Coleta Seletiva de Resíduos Sólidos (CSRS).

PALAVRAS-CHAVE: Educação ambiental. BNCC. Ensino.

\section{ABSTRACT}

The concept of environmental education is distinguished by the biases of the place of application of this. The formation and development of the individual also take place in educational institutions and therefore the principles that make up the recent change from LDB to National Curricular Common Ground (BNCC) need to be clear and equipped with pedagogy so that environmental education can be developed in the large proposed areas, Since students should opt for an area. The concern is that it is not possible to fully develop environmental education through the proposal to flexibilize the curriculum. This article aims to evaluate the pedagogical character of environmental education in the changes of the Brazilian High School Reform and in the BNCC, in the itineraries of the Natural Sciences and its social and applied human sciences and technologies. For that, a bibliographic survey was carried out in the scientific literature on environmental education: theory and applicability for the construction of reflections on the National Curricular Common Base (BNCC) and its approach to EE. After reading the NCPs, the impression of an ideal school, much more than that contemplated by the infrastructure of the Brazilian public schools, especially with regard to the laboratory aspects, remained. Due to its continued character, the school must adopt a policy and practices that allow the integrated development of Environmental Education in the school environment. To do this, some themes can be developed at school and in your community. We suggest a start project based on the investigation of the Selective Collection of Solid Residues (CSRS).

KEY WORDS: Environmental education. BNCC. Teaching

\section{RESUMEN}

El concepto de educación ambiental se distingue por los sesgos de este sitio de aplicación. La formación y el desarrollo del individuo también se llevan a cabo en las instituciones educativas y por lo tanto los principios que conforman el reciente cambio de LDB de Currículo Nacional Base Común (BNCC) tiene que ser claro y dotado de pedagogía para que la educación ambiental se desarrollará en grandes áreas propuestas ya que los estudiantes deben elegir un área. La preocupación es que no se puede desarrollar a su máximo la educación ambiental a través de la flexibilidad propuesta del plan de estudios. Este artículo tiene como objetivo evaluar el carácter pedagógico de la educación ambiental en los cambios de la reforma brasileña High School y BNCC en el contenido de los itinerarios de las ciencias y tecnologías naturales y las ciencias sociales y humanas aplicadas. Con este fin, se realizó la revisión de la literatura la literatura científica sobre la educación ambiental: teoría y aplicación a la construcción de 


\section{da Alta Paulista}

reflexiones sobre el Curriculum Nacional Base Común (BNCC) y su enfoque de EA. Después de leer el PCN, la impresión de una escuela ideal mismo ha conseguido, más allá de lo contemplado por la infraestructura de las escuelas públicas brasileñas, especialmente con respecto a los aspectos de laboratorio. Al tener función continua, la escuela debe adoptar una política y prácticas para el desarrollo integral de la educación ambiental en las escuelas. Con este fin, algunos temas se pueden desarrollar en la escuela y en su comunidad. Se sugiere un proyecto de inicio de la investigación de recogida selectiva de residuos sólidos (CSR).

PALABRAS CLAVE: Educación ambiental. BNCC. Educación. 
INTRODUÇÃO

Em um universo, onde as variáveis do meio físico - clima, solo, relevo, recurso hídrico e biodiversidade - se (re)combinam com às culturais, isto é, com as técnicas de apropriação da natureza construídas pelo Homem, forma-se uma gama de paisagens complexas e distintas que ao longo do espaço/tempo cada qual apresenta uma fragilidade e potencialidade ambiental específica, reafirma-se a importância de compreender a interação dos elementos e processos que compõem o Meio por meio da educação ambiental (EA). Permitindo que o Homem, sujeito ativo dessas paisagens, possa intervir no ecossistema de maneira sensível, fazendo com que os processos ecológicos sejam prioridades dentro do sistema da sustentabilidade ambiental.

O conceito de educação ambiental se diferencia pelos vieses do local de aplicação desta (Estado, ensino formal, setor público e setor coorporativo). Neste artigo, destaca-se a compreensão da EA por parte do aparato ideológico e legal do Estado brasileiro, uma vez que a Lei de Diretrizes e Base da Educação Nacional em conjunto com os Parâmetros Curriculares Nacionais norteavam os conteúdos e os fins didático-pedagógicos e influenciava diretamente no ensino formal das escolas brasileiras. Ressalta-se que a Política Nacional de Educação Ambiental de Lei $n^{\circ}$ 9.795/1999 compreende a mesma como sendo o conjunto de processos que possibilita a construção de valores, conhecimentos, técnicas e práticas sociais que viabilizam a conservação e sustentabilidade do meio ambiente. Já as Diretrizes Nacionais para a educação ambiental referem-se à mesma como uma dimensão da Educação que deve atingir o objetivo de ensinar e orientar as práticas humanas por meio da ética ambiental.

Entretanto, os teóricos da educação formal apresentam divergência conceitual sobre o que é a educação ambiental, sendo esta divergência salutar, pois trata da construção filosófica para o firmamento deste conceito. Os mesmos podem perpassar por uma ou mais correntes, as pioneiras (naturalista, conservacionista/recursista, resolutiva, sistêmica, científica, humanista, moral/ética) e as mais recentes (holística, biorregionalista, práxica, crítica, feminista, etnográfica, eco-educação, sustentabilidade). Estas se diferenciam em função da concepção de meio ambiente, intenção da educação ambiental e enfoques privilegiados (SAUVÉ, sd.). Para Sauvé (2005), a EA não se trata de uma educação de finalidade, ou seja, não pode ser compreendida como uma ferramenta para solução dos conflitos ambientais, mas sim como aquela responsável pela formação e desenvolvimento individual, no que tange os aspectos da interação do Homem para como meio.

A educação ambiental visa a induzir dinâmicas sociais, de início na comunidade local e, posteriormente, em redes mais amplas de solidariedade, promovendo a abordagem colaborativa e crítica das realidades socioambientais e uma compreensão autônoma e criativa dos problemas que se apresentam e das soluções possíveis para eles (SAUVÉ, 2005, p. 317)

Neste sentido, a formação e desenvolvimento do indivíduo também acontecem nas instituições de ensino e, portanto os princípios que compõem a recente alteração da LDB para Base Nacional Comum Curricular (BNCC) precisam ser claros e dotados de pedagogia para que a educação ambiental seja desenvolvida nas grandes áreas propostas (Linguagens, Códigos e suas tecnologias, Matemática e suas tecnologias, Ciências da natureza e suas tecnologias, 
Ciências humanas e sociais aplicadas e Formação técnica e profissional), uma vez que os alunos deverão optar por uma área. A preocupação é que não seja possível desenvolver em sua plenitude a educação ambiental por meio da proposta de flexibilização da grade curricular, levando em consideração que assuntos ligados ao meio ambiente possuem a adjetivação interdisciplinar. Sendo assim, este artigo tem como objetivo avaliar o caráter pedagógico da educação ambiental nas alterações da Reforma do Ensino Médio brasileiro e na BNCC, nos conteúdos itinerários das Ciências da natureza e suas tecnologias e Ciências humanas sociais e aplicadas.

\section{METODOLOGIA}

Este artigo é de cunho conceitual e tais procedimentos metodológicos tratam-se do levantamento na literatura científica sobre a educação ambiental: teoria e aplicabilidades para a construção de reflexões sobre a Base Nacional Comum Curricular (BNCC) e a sua abordagem de $E A$, segundo a reforma do ensino médio brasileiro.

\section{DISCUSSÕES}

\section{BASE NACIONAL COMUM CURRICULAR (BNCC) E A EDUCAÇÃO AMBIENTAL}

A Base Nacional Comum Curricular (BNCC) considera que o sentido normativo das competências e diretrizes para o ensino formal (instituições de ensino) afirma que os currículos são diversos. De acordo com o CNE/CEB no 5/2011 (2011), o ensino médio deve ofertar, em sua composição diversificada, conteúdos heterogêneos de múltiplos interesses, conforme os interesses de cada aluno. $O$ aluno do ensino médio escolherá por qual eixo de grandes áreas enfocará seus estudos (Linguagens, Códigos e suas tecnologias, Matemática e suas tecnologias, Ciências da natureza e suas tecnologias, Ciências humanas e sociais aplicadas e suas tecnologias e Formação técnica e profissional).

A ideia que parece revolucionária, ou seja, deixar que os mesmos aprofundem o conhecimento científico na sua futura área de formação superior. Porém, deve-se apontar que "[...] a infraestrutura da grande maioria das escolas públicas e das péssimas condições de trabalho dos docentes e sua desvalorização profissional." As escolas sem laboratórios, equipamentos e demais infraestruturas conseguirão cumprir com o proposto? Os alunos irão de fato atingir análises mais profundas em qualquer uma dessas grandes áreas? Já que para tal, está sendo sacrificado o conhecimento, mesmo que regular, em todas as outras disciplinas curriculares (Geografia, Biologia, Sociologia, Filosofia, Química, Física) que foram diluídas nas demais grandes áreas - itinerários formativos.

A diluição destas ciências ocasionará um impacto perverso no ensino médio, em que a lógica passará para um professor formado em Sociologia, por exemplo, ministrando conteúdos aos quais ele não teve formação, como dinâmica e processos naturais do planeta (Geografia) e vice e versa (CASTILHO, 2017). Os PCN's das grandes áreas (itinerários formativos) apresentam uma tentativa de articulação entre as mesmas, em que determinados conteúdos educacionais 


\section{da Alta Paulista}

podem e devem ser trabalhados em um itinerário formativo. Porém, não foram mencionadas as formas de se fazer esta correlação entre assuntos tão desconexos. Como ficará a abordagem dos temas transversais, sem a garantia de que os conceitos e princípios de cada disciplina diluída estejam sendo trabalhados sem prejuízo de construção do conhecimento?

A Educação ambiental enquanto disciplina ou conteúdo curricular é abordado de forma inter, multi ou transdisciplinarmente, isto é, para o seu desenvolvimento pleno é preciso a articulação de diversos conhecimentos e de disciplinas distintas. Na multidisciplinaridade, cada disciplina aborda o mesmo tema por meio da sua metodologia específica. Na interdisciplinaridade existe a troca de conhecimento entre as disciplinas e a cooperação destas para a análise do tema, porém cada disciplina ainda enfoca no seu objetivo. Já na transdisciplinaridade (ideal), o objetivo da análise é comum, e utiliza-se do conhecimento de várias disciplinas para analisar o tema proposto.

No Art. $2^{\circ}$ da Política Nacional de Educação Ambiental, esta componente é conteúdo permanente da educação nacional, formal e não formal. E está prevista em todos os níveis (básica, infantil, fundamental, média, superior, especial, profissional e de jovens e adultos). No Art. 10, A EA não deve ser implementada como uma disciplina específica, porém a mesma deve ser praticada de forma, integrada, contínua e permanente. A junção das disciplinas em conteúdos itinerários apresenta perdas no que tange aos métodos e procedimentos técnicos de cada uma, sendo que cada ramo do conhecimento científico também apresentam linguagens que não se comunicam de forma tão simples. Ocorrerão problemas de ordem metodológica nas bases conceituais de cada ciência. Desta maneira, questiona-se como aplicar a interdisciplinaridade entre os conteúdos itinerários para promover a educação ambiental assegurada pela Política Nacional de Educação Ambiental?

\section{PCN CIÊNCIAS DA NATUREZA E SUAS TECNOLOGIAS E A EDUCAÇÃO AMBIENTAL}

Segundo o PCN, este itinerário formativo poderá formar o aluno por meio de uma base conceitual que propicie desenvolver a educação ambiental, tendo como ponto de partida a diversidade de organismos presentes na Terra, bem como se dá a relação dos mesmos para com o ambiente. Porém, destaca-se que a palavra Educação Ambiental não aparece no texto, sendo que esta é considerada um tema transversal da educação formal. Os conteúdos da Biologia estão organizados em seis temas (1. interação entre os seres vivos; 2 . qualidade de vida das populações humanas; 3 . identidade dos seres vivos; 4 . diversidade da vida; 5. transmissão da vida, ética e manipulação gênica; 6 . origem e evolução da vida.)

Assim, os conteúdos de Biologia devem propiciar condições para que o educando compreenda a vida como manifestação de sistemas organizados e integrados, em constante interação com o ambiente físico-químico. O aluno precisa ser capaz de estabelecer relações que the permitam reconhecer que tais sistemas se perpetuam por meio da reprodução e se modificam no tempo em função do processo evolutivo, responsável pela enorme diversidade de organismos e das intrincadas relações estabelecidas pelos seres vivos entre si e com o ambiente. $O$ aluno deve ser capaz de reconhecer-se como organismo e, portanto, sujeito aos mesmos processos e fenômenos que os demais. Deve, também, reconhecer-se como agente capaz de 
modificar ativamente o processo evolutivo, alterando a biodiversidade e as relações estabelecidas entre os organismos. P.20

Após a leitura do PCN, fica-se a impressão de uma escola ideal, muito além daquela contemplada pela infraestrutura das escolas públicas brasileiras, sobretudo, no que tange aos aspectos de Laboratório. Já que na metodologia indicada pelo próprio, estes conteúdos devem ser trabalhados por meio da experimentação. O texto não menciona a capacitação dos professores para o desenvolvimento das pesquisas experimentais e de desenvolvimento de projetos na escola. Acesso à tecnologia para desenvolver a capacidade de investigação é importante. Nos países desenvolvidos a infraestrutura dos laboratórios de pesquisa é, em sua grande maioria, tecnológica. No PCN ao invés de se discutir a necessidade de equipar as escolas públicas aparece o seguinte trecho "As habilidades necessárias para que se desenvolva o espírito investigativo nos alunos não estão associadas a laboratórios modernos, com equipamentos sofisticados." (MEC, 2006, P. 26)

Os conteúdos de Biologia que aparecem no PCN e podem ser utilizados para se trabalhar a educação ambiental são: o destino do lixo e do esgoto, o tratamento dado à água, o modo de ocupação do solo, as condições dos rios e córregos e a qualidade do ar. Quando se analisa os conteúdos mínimos da ciência biológica fica-se evidente que muitos outros elementos podem ser utilizados para a EA, como por exemplo: questões do desmatamento e perda de biodiversidade.

A física é importante para desenvolver a capacidade de investigação das leis que regem o meio e como esta responde às alterações do Homem na paisagem. Desta maneira, os conceitos deste ramo científico também são importantes para desenvolver as faculdades dos alunos em EA. No PCN da física destacou-se para emprego na Educação ambiental "identificar regularidades, associando fenômenos que ocorrem em situações semelhantes para utilizar as leis que expressam essas regularidades na análise e previsões de situações do dia-a-dia." (MEC, p. 65). Os conteúdos da física do novo ensino médio estão organizados em seis temas:

1-Movimento, variações e conservações (unidades temáticas: fenomenologia cotidiana, variação e conservação da quantidade de movimento, energia e potência associadas aos movimentos, equilíbrios e desequilíbrios). 2- Calor, ambiente e usos de energia (unidades temáticas: fontes e trocas de calor, tecnologias que usam calor: motores e refrigeradores, o calor na vida e no ambiente, energia: produção para uso social). 3- Som, imagem e informação (unidades temáticas: fontes sonoras, formação e deteç̧ão de imagens, gravação e reprodução de sons e imagens, transmissão de sons e imagens), 4- Equipamentos elétricos e telecomunicações (unidades temáticas: aparelhos elétricos, motores elétricos, geradores, emissores e receptores). 5Matéria e radiação (unidades temáticas: matéria e suas propriedades, radiações e suas interações, energia nuclear e radioatividade, eletrônica e informática) e 6Universo, Terra e vida (unidades temáticas: Terra e sistema solar, o universo e sua origem, compreensão humana do universo). (MEC, 2006, PP. 50-51)

Os estudos em Química podem auxiliar os temas em Educação Ambiental correlacionado a origem, evolução e leis do Universo e do Planeta Terra. Como exemplo da importância da Química para a EA, pode-se citar temas como tempo de degradação dos resíduos na natureza (Figura 1), bem como a mudança de estado da matéria das substâncias são objetos 
corriqueiros da EA e utilizam conceitos da ciência química para que os alunos compreendam a temática e se sensibilizem, fazendo com que os mesmos entendam a importância de contribuir com a coleta seletiva dos resíduos que já é realizada em muitas cidades brasileiras.

Figura 1: Tempo de degradação de resíduos sólidos, conteúdo transversal de Educação Ambiental.

\begin{tabular}{|c|c|c|}
\hline UMA COR PARA CADA TIPO DE LIXO & \multicolumn{2}{|c|}{ TEMPO DE DECOMPOSIÇĀC } \\
\hline \multirow{3}{*}{ Papel/papelão } & Vidro & Indeterminado \\
\hline & Lata de aço & 50 anos \\
\hline & Garrafa plástica & 450 anos \\
\hline \multirow{2}{*}{ Plástico } & Copo plástico & 50 anos \\
\hline & Lixo radioativo & 250.000 anos \\
\hline \multirow{3}{*}{ Vidro } & Caixa de papelăo & 2 meses \\
\hline & Lata de aluminio & 200 anos \\
\hline & Madeira pintada & 13 anos \\
\hline \multirow{2}{*}{ Metal } & Jornal & 6 meses \\
\hline & Chiclete & 5 anos \\
\hline
\end{tabular}

Fonte: Ministério do Meio Ambiente (2013).

É relevante destacar que como a EA não é uma disciplina do currículo forma, é importante que as diversas disciplinas dos grupos itinerários tenham condições de tratar temas comuns e que juntos analisem em todos os aspectos metodológicos assuntos ligados á EA. Segundo o PCN das Ciências da natureza e suas tecnologias, um mesmo tema é abordado de forma diferente por cada disciplina, mas que juntos somatizam para a compreensão do Objeto de estudo. Ao trabalhar o ciclo da água na Física, Biologia e Química "[...] a Física releva os aspectos das transformações de estado e processos de circulação, enquanto a Química trata das diferentes reações e do papel das soluções, enquanto a Biologia analisa a influência nas cadeias alimentares e o uso do solo." (MEC, 2006, PP. 50-51)

No PCN da Química espera-se que os seguintes eixos temáticos possam auxiliar no processo cognitivo em E.A: 1. Reconhecimento e caracterização das transformações químicas 2. Primeiros modelos de constituição da matéria 3. Energia e transformação química 4. Aspectos dinâmicos das transformações químicas 5. Química e atmosfera 6. Química e hidrosfera 7. Química e litosfera 8. Química e biosfera 9. Modelos quânticos e propriedades químicas

\section{PCN CIÊNCIAS HUMANAS E SUAS TECNOLOGIAS E A EDUCAÇÃO AMBIENTAL}

O PCN das Ciências Humanas e suas tecnologias apresentam como finalidade reunir os conhecimentos que possibilitarão com que os alunos compreendam os elementos cognitivos (sociais e culturais). Este rol de conhecimento tem a responsabilidade, pois proporciona a formação do cidadão, que também é um objetivo comum à EA.

Este documento entende que a História apresenta o papel de formar conceitos sobre (grupos sociais, culturas, gerações do passado e futuro), tratados em um período histórico. O que é importante, pois para o desenvolvimento das faculdades em EA compreender a ação humana no passado, pode re(significar) as ações da sociedade no presente, sobretudo nas temáticas de 


\section{da Alta Paulista}

preservação ambiental, visto que muitos animais já foram extintos, em decorrência dos modelos econômicos e formas de apropriação da natureza ao longo do tempo/espaço.

A Geografia é uma ciência importante, pois permite compreender a ação humana no espaço, isso é meio ambiente, e esta trata diversos conceitos que envolvem tanto a construção humana, quanto o funcionamento da natureza e da paisagem. Para o novo PCN de Geografia do ensino médio, "[...] nunca o espaço do homem foi tão importante para o desenvolvimento da história. Por isso, a Geografia é a ciência do presente."(MEC, 2006, p. ). Se esta ciência é tão importante, como de fato ela é, por que a mesma será retirada como disciplina do ensino médio? Na educação ambiental é importante a construção fundamentada das categorias da Geografia, pois é possível trabalhar a EA, por meio, de diversas abordagens metodológicas (território, lugar, paisagem, região e espaço geográfico). Assim, a Geografia do ensino médio contribui para o aluno:

Analisar e comparar, interdisciplinarmente, as relações entre preservação e degradação da vida no planeta, tendo em vista o conhecimento da sua dinâmica e a mundialização dos fenômenos culturais, econômicos, tecnológicos e políticos que incidem sobre a natureza, nas diferentes escalas - local, regional, nacional e global. (MEC, 2006)

No que tange aos conhecimentos de sociologia segundo o novo PCN, esta ciência possui o caráter de relevar as instituições sociais (família, Estado e outros), e como as relações destas constituem os direitos e deveres da sociedade. Desta forma, em Educação Ambiental, os pressupostos sociológicos devem auxiliar o aluno a compreender dentro da ética e conduta social, a organização do meio ambiente, bem como nortear as boas práticas no meio ambiente. E trabalhar a Filosofia em Educação Ambiental é fundamental, pois garante o pensar o Meio Ambiente (razão de quem pensa, revela, e reflete), isto é esta abarca a reconstrução e o exercício de caráter analítico, se voltando para os princípios de investigação sobre as problemáticas trazidas por meio da EA.

\section{A COLETA SELETIVA DE RESíduOS SÓlidos (CSRS) COMO TEMA PARA SE TRABALHAR A EDUCAÇÃO AMBIENTAL NO ENSINO MÉDIO}

Para se trabalhar a Educação Ambiental no âmbito formal (escolar) é preciso que esta atinja pelo menos a abordagem interdisciplinar. Nestas instituições a escola não deve apresentar apenas caráter instrutivo, mas também formativo de valores morais, sociais e políticos. Os temas sobre o Meio Ambiente são tratados pela mídia, porém na escola estes mesmos temas devem ser trabalhados de forma integrada para formar os cidadãos participativa e criticamente. Assim, a EA nas escolas pretende: “[...]modificar esta forma arraigada de ver a educação, tornando-a mais contextualizada, mais próxima da realidade do aluno, sem contudo criar novas disciplinas" (SILVA, 2002, p. 49). Conforme Silva (2002), a educação ambiental ao tratar o tema transversal Meio Ambiente não pode ser reducionista em apenas dois temas (Ambiente e Vida), é possível abordar diversas temáticas, inclusive abrangendo o conteúdo itinerário das Ciências Humanas e suas tecnologias. 


\title{
da Alta Paulista
}

Levando em consideração as deficiências dos laboratórios das escolas públicas brasileiras, o professor terá que contornar essa adversidade, utilizando-se de outras tecnologias, tais como vídeos e documentários já produzidos para demonstrar as tecnologias existentes e as diversas metodologias de análise necessárias param se trabalhar a Educação Ambiental. Moran (2000) apud Silva (2002) destaca os vídeos com forma de sensibilização, ilustração, simulação, conteúdo de ensino, e de produção no âmbito escolar.

Por ter característica continuada, a escola deverá adotar uma política e práticas que permitam o desenvolvimento integrado da Educação Ambiental no âmbito escolar. Para tal, alguns temas podem ser desenvolvidos na escola e em sua comunidade. Sugere-se um projeto start a partir da investigação da Coleta Seletiva de Resíduos Sólidos (CSRS), tratamento e destino final. Apesar de o assunto ser assunto já ter sido muito discutido nas instituições de ensino, a coleta seletiva dos resíduos sólidos domésticos, ainda não é efetiva. Pois, a população ainda não se sensibilizou para esta causa. Devido a periculosidade do impacto ocasionado pela elevada produção de resíduos sólidos e o precário gerenciamento dos mesmos até o local de destino final (Aterros ou lixões), tanto o Meio Ambiente quanto a saúde humana são prejudicados, por isto, a abordagem desta temática de forma interdisciplinar, é um tema urgente e atual. Ressalta-se a importância de desenvolver cidadãos críticos, capazes de modificar o meio, fazendo com que a CSRS se torne de fato uma prática social.

\begin{abstract}
O lixo é tecnicamente chamado de resíduo sólido e pode ser considerado como qualquer material que seu proprietário ou produtor não considera mais com valor suficiente para conservá-lo. Por outro lado, o lixo resulta da atividade humana, sendo, por isso, considerado inesgotável, além de diretamente proporcional à intensidade industrial e ao aumento populacional. Por esse motivo, uma das grandes preocupações da sociedade atual diz respeito aos resíduos sólidos. O crescimento desordenado da população e o aparecimento de grandes indústrias têm aumentado o consumo e com isso gerado maior quantidade de resíduos, que, geralmente, possuem manejo e destino inadequados, provocando, assim, efeitos indesejáveis ao meio ambiente.
\end{abstract}

Com base nos PCN's do novo ensino médio analisados, apontou-se ideias que podem ser desenvolvidas pelas ciências (Biologia, Física, Química, Geografia, História, Sociologia e Filosofia) no desenvolvimento interdisciplinar para a temática CSRS, Quadro 1. 


\section{da Alta Paulista}

Figura 1: Tempo de degradação de resíduos sólidos, conteúdo transversal de Educação Ambiental.

\begin{tabular}{|c|c|c|c|}
\hline & $\begin{array}{l}\text { Identificar os problemas } \\
\text { relacionados com a } \\
\text { CSRS na escola e na } \\
\text { comunidade }\end{array}$ & $\begin{array}{l}\text { Diagnóstico sobre problemas } \\
\text { existentes, no gerenciamento } \\
\text { de resíduos e dos impactos } \\
\text { ambientais ocasionados }\end{array}$ & $\begin{array}{l}\text { Atividades estratégicas com } \\
\text { base na educação ambiental }\end{array}$ \\
\hline Biologia & Natureza dos RS & $\begin{array}{l}\text { Degradação do meio ambiente } \\
\text { e biodiversidade }\end{array}$ & $\begin{array}{l}\text { Apresentações e seminários } \\
\text { sobre a biodiversidade local e } \\
\text { suas características genéticas }\end{array}$ \\
\hline Física & $\begin{array}{l}\text { Estado da matéria dos } \\
\text { RS }\end{array}$ & $\begin{array}{l}\text { Investigação da sinergia dos } \\
\text { fluxos de energia e matéria do } \\
\text { meio }\end{array}$ & $\begin{array}{l}\text { Experimentos comparando o } \\
\text { funcionamento do meio } \\
\text { saudável e o poluído }\end{array}$ \\
\hline Química & $\begin{array}{lr}\text { Composição } & \text { e } \\
\text { decomposição } & \text { química } \\
\text { dos RS } & \\
\end{array}$ & $\begin{array}{l}\text { Mudanças na qualidade do solo } \\
\text { e do recurso hídrico }\end{array}$ & $\begin{array}{l}\text { Análises químicas do solo, da } \\
\text { água e da atmosfera }\end{array}$ \\
\hline Geografia & $\begin{array}{l}\text { Impactos ambientais e } \\
\text { análises } \\
\text { socioeconômicas na } \\
\text { geração dos RS }\end{array}$ & $\begin{array}{lr}\text { Levantamento } & \text { das } \\
\text { coordenadas e } & \text { caracterização } \\
\text { dos passivos } & \text { ambientais } \\
\text { encontrados }\end{array}$ & $\begin{array}{l}\text { Elaboração da cartografia dos } \\
\text { problemas ambientais } \\
\text { encontrados }\end{array}$ \\
\hline História & $\begin{array}{ll}\text { Contextualização } & \text { da } \\
\text { comunidade e } & \text { da } \\
\text { produção dos RS } & \end{array}$ & $\begin{array}{llr}\text { Relação } & \text { entre } & \text { impacto } \\
\text { ambiental } & \text { e as } & \text { diferentes } \\
\text { sociedades } & & \\
\end{array}$ & $\begin{array}{l}\text { Exposição dos diferentes } \\
\text { resíduos sólidos para cada } \\
\text { sociedade }\end{array}$ \\
\hline Sociologia & $\begin{array}{l}\text { Explicitação das relações } \\
\text { existentes na sociedade } \\
\text { do consumo }\end{array}$ & $\begin{array}{l}\text { Identificação e caracterização } \\
\text { dos agentes envolvidos neste } \\
\text { processo }\end{array}$ & $\begin{array}{l}\text { Provocar o } r \text { debate } \\
\text { argumentativo no } \\
\text { escolar }\end{array}$ \\
\hline Filosofia & $\begin{array}{l}\text { Formação intelectual do } \\
\text { cidadão, sensibilização e } \\
\text { mudança de prática do } \\
\text { indivíduo }\end{array}$ & $\begin{array}{l}\text { Tratamento de diferentes } \\
\text { métodos de concepção de } \\
\text { mundo }\end{array}$ & $\begin{array}{l}\text { Auxiliar a comunicação e } \\
\text { construção de relação entre a } \\
\text { comunidade e a escola para a } \\
\text { sensibilização da temática } \\
\text { sugerida }\end{array}$ \\
\hline
\end{tabular}

\section{CONCLUSÃO}

A mudança do Ensino Médio proposta e aprovada pelo MEC para as instituições de ensino brasileiro (públicas e privadas) gera bastante polêmica entre os profissionais da educação. Considerando, que algumas ciências serão aglutinadas em grupos, os chamados conteúdos itinerários, da falta de capacitação dos docentes para tal mudança, bem como sobre a falta de infraestrutura das escolas, sobretudo das públicas.

Este trabalhou analisou os PCN's das Ciências da natureza e suas tecnologias e o das Ciências Humanas e Sociais aplicadas, buscando compreender os conteúdos mínimos presentes a ser desenvolvidos nestas áreas, bem como, buscou-se correlacionar as áreas para a proposição de um tema para tentar desenvolver, por meio da Educação ambiental, a interdisciplinaridade no âmbito da escola. Mesmo sabendo que a EA não é uma disciplina curricular, é um falha não aparecer nem uma vez, nos PCN's, referência à mesma, nem sugestão de como cada conteúdo mínimo pode contribuir no processo da EA.

É fato que desenvolver a interdisciplinaridade na escola é uma forma de tornar os cidadãos críticos. Porém, o fato dos alunos escolher por qual conteúdo itinerário vão cursar, segundo a sua escolha de área que pretendam seguir, em um primeiro momento, atribui caráter de especialização a jovens que ainda precisam aprender os conteúdos gerais de diversas ciências para desenvolvimento das atividades cognitivas que levarão ao entendimento de mundo. 
Sendo que esta especialização tem elevada chance de fracassar, pois as escolas apresentam infraestrutura frágil (laboratórios precários), recurso humano desmotivado e com pouca capacitação. A real ameaça é o fato de que os alunos poderão ter contato superficial com apenas uma área (escolhida por eles) e fiquem sem o desenvolvimento de conceitos básicos dos demais conteúdos itinerários.

Como a Educação Ambiental contribui para a formação do individuo e aborda as relações humanas para com o meio de forma interdisciplinar, necessita-se dos conceitos, métodos e metodologias de todas as disciplinas do antigo currículo para o desenvolvimento da mesma. Diante disso, conclui-se com um questionamento: Como trabalhar a Educação Ambiental no novo ensino médio brasileiro, se os alunos irão optar por apenas um conteúdo itinerário?

\section{AGRADECIMENTO}

Agradecemos à Universidade Estadual de Goiás pelo financiamento da Pesquisa por meio do edital Próprojetos/pesquisa $n^{\circ} 029 / 2016$.

\section{REFERÊNCIAS BIBLIOGRÁFICAS}

SAUVÉ, Lucie. Educação ambiental: possibilidades e limitações. Educação e Pesquisa. São Paulo, v.31. n.2, p.317322, maio/ago. 2005.

SAUVÉ, Lucie. Uma cartografia das correntes em Educação ambiental. Disponível em:< http://web.unifoa.edu.br/portal_ensino/mestrado/mecsma/arquivos/sauve-I.pdf> Acesso em abr. 2017.

DANCINGUER, Marli. Educação ambiental e ensino de física. Disponível: http://www.fisicajp.unir.br/downloads/1995_tccmarli.pdf Acesso em abr. 2017.

Ministério da Educação (MEC). PCN do Ensino média: Ciências da Natureza, matemática e suas tecnologias. Disponível em:http://portal.mec.gov.br/seb/arquivos/pdf/CienciasNatureza.pdf Aceso em abr. 2017.

Ministério do Meio Ambiente (MMA). Tempo de decomposição dos recursos sólidos. Disponível em: <http://blog.mma.gov.br/separeolixo/coleta-seletiva-de-residuo-lixo/> Acesso em abr. 2017.

Ministério da Educação (MEC). PCN do Ensino médio: Ciências Humanas e suas tecnologias. Disponível em: <http://portal.mec.gov.br/seb/arquivos/pdf/cienciah.pdf> Acesso em abr. 2017.

SILVA, Ângela dos Santos Maia Nogueira da. Um Olhar sobre a Educação Ambiental no Ensino Médio: Praticar a Teoria, Refletir a Prática. Dissertação de Mestrado. Florianópolis, 2002. Disponível em:< https://repositorio.ufsc.br/bitstream/handle/123456789/85470/226169.pdf?sequence=1.> Acesso abril. 2017. 